\title{
Editorials
}

\section{Developing middle-ground research to support primary care transformation}

Healthcare systems across the world are facing common challenges relating to changing demographics, and in particular ageing populations. In the UK multimorbidity is a key common denominator in frailty in older people, and health inequalities in younger age groups. ${ }^{1,2}$ There is substantial divergence in how the four nations of the UK are responding to this challenge. ${ }^{3}$ In this editorial we describe the Scottish approach to primary care transformation and how better evidence to support transformation can be generated in countries undergoing healthcare reforms.

\section{PRIMARY CARE TRANSFORMATION IN SCOTLAND}

The Scottish Government has recently embarked on an ambitious journey to transform the health and social care system, with primary care at the heart of this. ${ }^{4,5}$ Numerous new models of primary care are currently being piloted, and an evaluation is being undertaken by the Scottish School of Primary Care la consortium of Scottish universities with a strong track record in academic primary care). Following the abolition of the Quality and Outcomes Framework in Scotland in 2016, a new Scottish GP contract will be rolled out in 2018 and will include a fresh approach to quality improvement with a requirement for GP practices to work in Quality Clusters. The clusters are expected to lead both healthcare quality improvement focused on local needs, and the engagement of GPs in the wider integration agenda.

These radical changes in Scotland are underpinned by the Chief Medical Officer's (CMO) vision for 'realistic medicine', with the key principles of:?

- moving towards shared decision making;

- building a personalised approach to care;

- reducing harm and waste;

- reducing unnecessary variation in practice and outcomes;

- managing risk better; and

- becoming improvers and innovators.

These principles apply not only to medicine, but also to the entire health and social care system. In her 2016 report Realising Realistic Medicine, the CMO identifies connecting, collaboration, communication, and culture as the key tools for delivering realistic medicine. The report acknowledges the need for

\begin{tabular}{|c|c|c|}
\hline & $\begin{array}{l}\text { Frontline clinicians and } \\
\text { managers }\end{array}$ & Academics \\
\hline $\begin{array}{l}\text { Creating } \\
\text { interventions and } \\
\text { new models of care }\end{array}$ & $\begin{array}{l}\text { Normal business for NHS } \\
\text { innovators. Strong on feasibility } \\
\text { but often does not draw on } \\
\text { strongest existing theory and } \\
\text { evidence }\end{array}$ & $\begin{array}{l}\text { Normal business for health services } \\
\text { researchers. Strongly based on } \\
\text { existing theory and evidence but often } \\
\text { inadequate attention paid to feasibility }\end{array}$ \\
\hline $\begin{array}{l}\text { Evaluating } \\
\text { interventions and } \\
\text { new models of care }\end{array}$ & $\begin{array}{l}\text { Often not focused on from the } \\
\text { start, and evaluations done tend } \\
\text { to use weaker designs that have } \\
\text { significant risks of bias }\end{array}$ & $\begin{array}{l}\text { Emphasise pre-planned, 'as strong } \\
\text { as possible' evaluation design to } \\
\text { minimise bias }\end{array}$ \\
\hline $\begin{array}{l}\text { Translating new } \\
\text { ideas into practice } \\
\text { and ensuring spread } \\
\text { and sustainability }\end{array}$ & $\begin{array}{l}\text { The experts in real-world } \\
\text { implementation but often do } \\
\text { not draw on existing theory and } \\
\text { evidence }\end{array}$ & $\begin{array}{l}\text { Often underestimate the complexity of } \\
\text { real-world implementation and many } \\
\text { perceive translation to be someone } \\
\text { else's responsibility }\end{array}$ \\
\hline $\begin{array}{l}\text { Evaluating } \\
\text { widespread } \\
\text { implementation }\end{array}$ & $\begin{array}{l}\text { Often not focused on from the } \\
\text { start, and evaluations done tend } \\
\text { to use weaker designs that have } \\
\text { significant risk of bias }\end{array}$ & $\begin{array}{l}\text { Have relevant methodological } \\
\text { expertise but not commonly engaged } \\
\text { in real-world evaluation, although } \\
\text { now partly incentivised by Research } \\
\text { Excellence Framework requirements } \\
\text { to demonstrate impact }\end{array}$ \\
\hline
\end{tabular}

research to support and evaluate change. ${ }^{8}$ In primary care, where most patients in the $\mathrm{NHS}$ are seen, there is a particularly pressing need to develop robust evidence for how best to operationalise these principles.

\section{EVIDENCE-BASED REALISTIC MEDICINE}

Achieving the aims of primary care transformation and realistic medicine will require good evidence on what works, how such interventions can be implemented and scaled up, and effectiveness and costeffectiveness at system and population level. Some of this will require new large, high-quality, randomised controlled trials (RCTs) of complex interventions, given the dearth of such evidence in areas such as multimorbidity.? Such RCTs are naturally academic led with long timescales, which eventually require NHS-led work to implement. However, the traditional sequence of 'research' then 'development' is known to be slow and fallible, with research often not addressing service needs, and service development often ignoring research evidence. ${ }^{10}$ This reflects the fact that academics and NHS professionals all too often work in their individual silos with limited translation of research into practice, and limited evaluation of practice to maximise effectiveness. However, each group has complementary strengths and weaknesses, so effective collaboration has the potential for considerable mutual benefit (Box 1).

\section{DEVELOPING COLLABORATIVE INNOVATION AND MIDDLE-GROUND RESEARCH}

All the UK nations and other high-income countries across the world face major challenges in designing effective primary care systems for the complex future characterised by demographic change, increasing demand, constrained budgets, and rapidly evolving technology. An international workshop hosted by the Scottish School of Primary Care in Edinburgh in May 2017 highlighted just how similar these challenges are in different countries and, perhaps surprisingly, the similarity of many of the potential solutions being suggested. The resulting consensus statement generated from the meeting concluded that collaboration between policy makers and academics in primary care research could quickly improve quality and value, achieving greater health gain for citizens, by filling in current evidence gaps and guiding the adoption and delivery of policy directives.'

We believe there is an important innovative 'middle ground' that sits between the remit of national research funding bodies (who mainly fund tightly controlled research studies maximising internal validity where translation 


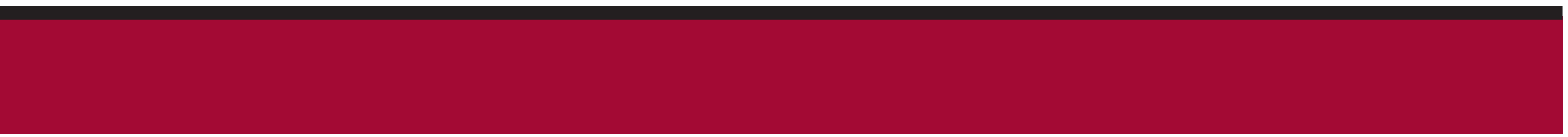

\section{"Middle-ground research offers an attractive approach by providing 'realistic research' over a much shorter time span ...}

\section{ADDRESS FOR CORRESPONDENCE}

Stewart Mercer

University of Glasgow, General Practice and Primary

Care, 1 Horselethill Road, Glasgow G12 9LX, UK.

E-mail: stewart.mercerlaglasgow.ac.uk is an aspiration rather than a deliverable) and NHS-funded service evaluations (which mainly examine impact after NHS-developed services are rolled out, but which are rarely designed in from the outset). NHS-academic collaboration to co-create and rigorously evaluate interventions and new models of care is potentially a highly productive way to develop evidence of effectiveness, to facilitate translation into widespread practice, and to ensure the evaluation of real-world implementation. A focus on this research middle ground could provide evidence for the effectiveness and cost-effectiveness of service developments within a relatively short time frame and help to deliver the evidence base for realistic medicine.

There are two types of middle-ground working. First, there is the evaluation of the implementation and impact of NHS-led innovation where collaboration can ensure that innovation is informed by research and evaluation is as robust as possible. The current work of the Scottish School of Primary Care on evaluating the primary care transformation projects is one example of this approach to complex evaluations. In partnership with NHS Health Scotland, the school has also helped establish a primary care evidence collaborative' of all the major NHS Scotland organisations that have a role in data collection, analysis, and evaluation, with a view to establishing a 10-year evaluation platform.

Second, there is the co-creation of complex interventions and new models of care that are evidence based, theory informed, and feasible for NHS implementation, and which have robust evaluation designed in from the outset to firmly establish impact and value for money. This type of focused, pragmatic research is often difficult to fund, because research funders often shy away from 'overly applied research' and NHS and policy funders shy away from 'overly academic innovation'.

Middle-ground research requires close collaboration between academics, policymakers, NHS managers, frontline staff, and patients. It exemplifies the approach needed to realise the vision of 'realistic medicine': by developing connections and building collaboration, we can create a different culture that delivers better evidence-based care for patients. ${ }^{7}$ The challenges involved in such collaboration should, of course, not be underestimated. In England, the well-funded NIHR Collaborations for Leadership in Applied Health Research and Care (CLARC) have met difficult challenges: the complexity of the evaluation, the importance of context, navigating boundaries, knowledge brokering, capacity building, and patient and public involvement. ${ }^{12}$ Nevertheless, there remains a compelling need to fill the many 'evidence gaps' in the road to transformation of primary care. Middle-ground research offers an attractive approach by providing 'realistic research' over a much shorter time span than traditional research, the findings of which would then be more rapidly implemented by NHS partners who were deeply involved from the outset. The middle-ground approach that we are proposing to inform Scotland's healthcare journey could also lead to and benefit from meaningful collaboration across the UK and internationally.

\section{Bruce Guthrie,}

Head of Population Health Sciences Division, Professor of Primary Care Medicine, University of Dundee, Dundee.

\section{John Gillies OBE,}

Honorary Professor of General Practice, University of Edinburgh, Edinburgh; Deputy Director, Scottish School of Primary Care, Glasgow.

\section{Catherine Calderwood,}

Chief Medical Officer for Scotland, Scottish Government; Consultant in Obstetrics and Gynaecology, Royal Infirmary of Edinburgh, Edinburgh.

\section{Gregor Smith,}

Deputy Chief Medical Officer for Scotland, Scottish Government; GP; Honorary Clinical Associate Professor, University of Glasgow, Glasgow.

\section{Stewart Mercer,}

Professor of Primary Care Research, University of Glasgow, Glasgow; Director, Scottish School of Primary Care, Glasgow.

\section{Provenance}

Commissioned; not externally peer reviewed.

DOI: https://doi.org/10.3399/bjgp17X693209

\section{REFERENCES}

1. Barnett K, Mercer SW, Norbury M, et al. Epidemiology of multimorbidity and implications for health care, research, and medical education: a cross-sectional study. Lancet 2012; 380(9836): 37-43.

2. Salisbury C, Johnson C, Purdy S, et al. Epidemiology and impact of multimorbidity in primary care: a retrospective cohort study. $\mathrm{Br}$ J Gen Pract 2011; DOI: https://doi.org/10.3399/ bjgp11X548929.

3. Bevan G, Karanikolos M, Exley J, et al. The four health systems of the United Kingdom: how do they compare? London: Health Foundation, 2014.

4. Scottish Government. Integration of health and social care. 2016. http://uww.gov.scot/ Topics/Health/Policy/Adult-Health-SocialCareIntegration (accessed 20 Sep 2017).

5. Scottish Government. A national clinical strategy for Scotland. 2016. http://wnw.gov. scot/Publications/2016/02/8699/downloads (accessed 20 Sep 2017).

6. Scottish Government. Improving together: a national framework for quality and GP clusters in Scotland. 2017. http://umw.gov.scot/ Publications/2017/01/7911 laccessed 20 Sep 2017).

7. Calderwood C. Realistic medicine: Chief Medical Officer's annual report 2014-15. 2016. http://mww.gov.scot/Resource/0049/00492520. pdf (accessed 20 Sep 2017)

8. Calderwood C. Realising realistic medicine: Chief Medical Officer's annual report 2015-16. 2017. http://www.gov.scot/ Resource/0051/00514513.pdf laccessed 20 Sep 2017).

9. Smith SM, Wallace E, O'Dowd T, Fortin M. Interventions for improving outcomes in patients with multimorbidity in primary care and community settings. Cochrane Database Syst Rev2016; 3: CD006560.

10. Grimshaw JM, Eccles MP, Lavis JN, et al. Knowledge translation of research findings. Implement Sci 2012; 7: 50.

11. Scottish School of Primary Care. Learning together: sharing international experience on new models of primary care; policy, delivery, and evaluation. SSPC, 2017. http://www.sspc ac.uk/media/media_538658_en.pdf laccessed 20 Sep 2017).

12. Kislov R, Boaden R. Evaluation of the NIHR CLAHRCS and publication of results: a brief reflection. 2015. http://clahrc-gm.nihr.ac.uk/ wp-content/uploads/CLAHRC-evaluationpublications-summary-Ruth-Boaden-andRoman-Kislov.pdf (accessed 27 Sep 2017). 